\title{
O QUARTO FANTASMA
}

\author{
Eugenio Barba - Odin Teatret ${ }^{2}$
}

\section{Um contínuo mutar}

Desde meus primeiros passos na profissão teatral, o treinamento tem sido um ponto de orientação constante sobre o qual muitas vezes tenho falado e escrito. Cruzei o campo minado das ilusões, mas não me posso dizer desiludido. A presença constante do treinamento é para mim um contínuo mutar sempre ao meu lado, já que não surgiu de uma doutrina, mas de minhas dúvidas e das questões que estas suscitaram.

Sinto, no entanto, inquietação a cada vez que tenho que falar sobre treinamento. Seria irresponsável considerá-lo um dogma teatral. Porém, seria da mesma forma um engano minimizar sua importância, tratando-o como uma miragem técnica ou como prática de uma minoria, de abrangência limitada.

Como de costume, quando tento abordar uma questão de um ponto de vista diferente, começo a mover-me para trás, retornando ao meu começo.

Estávamos no princípio dos anos 1960, eu não tinha sequer 30 anos. Jerzy Grotowski já se comportava como um mestre ancião, ainda que estivesse apenas se aproximando de seu trigésimo aniversário. No discurso, bem como na prática teatral daquele tempo, treinamento e exercícios eram inexistentes, descritos apenas em livros de historia do teatro, como prática incomum e excepcional nos estúdios de Stanislavsky e Meyerhold ou na escola de Jacques Copeau no Vieux Colombier.

Desde 1962, no pequeno Teatro das 13 Fileiras na provinciana cidade polonesa de Opole, os atores de Grotowski vinham praticando exercícios, além do trabalho com ensaios e espetáculos. Estes exercícios não eram experimentos, tampouco fragmentos a ser inseridos no espetáculo. Faziam parte do programa

${ }^{1}$ Traduzido do inglês por Deise Farias Nunes, artista cênica e estudante de teatrologia na Universidade de Oslo.

${ }^{2}$ Diretor do Odin Teatret e importante teatrólogo contemporâneo.

0 Quarto Fantasma. Eugênio Barba.

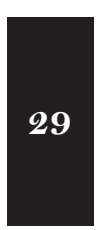


diário de trabalho. Originalmente, Grotowski havia selecionado os exercícios em vista do espetáculo que estava preparando. Usava, por exemplo, certas posições da Hatha Yoga, mudando meramente a sua dinâmica. Os exercícios continuavam sendo executados mesmo após a estréia do espetáculo, e com o tempo, tornaram-se seqüências básicas do treinamento, cadeias de exercícios 'físicos' e 'plásticos'.

Naquele período, no ambiente teatral europeu, falava-se de escritores: Sófocles, Shakespeare, Brecht, Chekov, ou os mais novos: Dürrenmat, Ionesco, Beckett. Os "grandes nomes" nos quais meus professores da escola de teatro em Varsóvia - e mais tarde também Grotowski - insistiam, eram de outra raça. Pertenciam ao reino do fazer, não do escrever: Stanislavsky, Vakthangov, Meyerhold, Osterwa, Tairov - os representantes da Grande Reforma que ocorreu durante as três primeiras décadas do século XX. E também o mímico Marcel Marceau, o redescobridor contemporâneo de um teatro sem palavras.

A primeira vez que escrevi sobre treinamento, em 1962, foi para listar e descrever os exercícios desenvolvidos por Grotowski em seu teatro. Eu almejava simplicidade, exatidão e racionalidade: um estilo similar a um "guia do usuário". Empreguei grande esforço na escolha de palavras que permitissem ao leitor praticar exercícios que ele jamais vira, e que pudessem liberar a sua imaginação. Nos anos seguintes, muitas vezes encontrei diretores e atores que me confessaram, sorrindo, seus enganos na tentativa de seguir as instruções do meu livro sobre Grotowski, À Procura de um Teatro Perdido (1965), republicado três anos mais tarde em Em Busca de um Teatro Pobre, de Grotowski.

Algumas destas pessoas, admitindo os equívocos causados pelos exercícios grotowskianos, também me contaram que, em sua perseverança, haviam inventado novos exercícios: o seu próprio treinamento. Cheguei a esta conclusão: mais importante do que a forma do exercício, é a motivação tenaz de executá-lo até os seus limites extremos, contribuindo desta forma para a sua mutação.

\section{A natureza diversa dos exercícios}

Nos livros dos reformadores do teatro, eu lia sobre visões sugestivas, mises-en-scène, e mais raramente, sobre exercícios. Logo me dei conta de que os exercícios são diferentes em sua natureza, sendo, em alguns casos, amuletos feitos de memória corporal: padrões pré-estabelecidos que poderiam ser repetidos como um mantra ou uma oração.

Esse era o caso, por exemplo, dos exercícios de biomecânica desenvolvidos por Meyerhold. Eram jóias do conhecimento teatral, tão complexos que dificilmente se lhes poderia avaliar, dos quais poucos fragmentos 
restaram filmados por seu criador. Basta que se tente imitá-los, para que se perceba a dificuldade em discernir os detalhes essenciais das partes que se pode modificar sem lhes causar dano. São formas fixas, porém não servem para transmitir uma forma, um estilo Meyerhold. Comunicam, através de uma forma perceptível, o pensamento-em-ação do ator: contrastes, contrapontos, a presença simultânea de múltiplas variações dinâmicas e de direção, dentro da mesma ação. São uma espécie de cubismo em ação, parecendo à primeira vista excêntricos e abstratos, mas que, se persistirmos em analisá-los, revelam a escrita pessoal, codificada, de um artesão e cientista do teatro.

Estes exercícios condensam um estranhamento físico e mental palpável. Eles decompõem gestos cotidianos e os recompõem, transformados e, ainda assim, orgânicos, isto é, sensorialmente persuasivos ao observador. Por outro lado, o ator que os executa é como um viajante que retorna a uma paisagem familiar após visitar a antípoda. Isto ocorre mesmo na ação mais simples: bater palmas, por exemplo. Em nosso comportamento cotidiano, primeiro abrimos os braços, para então bater palmas. Na biomecânica de Meyerhold, as mãos se encontram levemente afastadas, as palmas se batem, e então os braços se abrem. Trata-se de um estranhamento elementar, mas a partir deste simples exemplo podemos entender a lógica que move a partitura, complexa e intrincada, destes exercícios rigorosamente formalizados.

Um tipo completamente diferente de exercícios objetiva treinar habilidades específicas dos atores, no que concerne ao uso da voz e das ações físicas. Estes exercícios expandem a gama de possibilidades do ator, porém sem amarrá-lo a um estilo particular, a um comportamento cênico pré-estabelecido ou a uma série de clichês já experimentados, que arriscam restringir-lhe a liberdade. Liberdade significa escolha, e a escolha só é possível se feita a partir de uma abundância de possíveis alternativas, todas conhecidas e dominadas.

Ainda de outro gênero, são os exercícios centrados em variações rítmicas, na construção de inter-relações com outros atores bem como na composição do diálogo e do contato físico/vocal. Estas micro-situações amplificam a elasticidade na adaptação instantânea do ator aos estímulos dos outros atores e/ou do contexto, fortalecendo o caráter imediato da ação/ reação.

Há exercícios que se assemelham a 'jogos sociais' que estimulam a imaginação (a escolher um personagem e ser capaz de responder a qualquer questão posta pelos companheiros a respeito da vida e da forma de pensamento deste). Outros exercícios treinam reações corpóreas e percepção (todos correm ao redor da sala, e, a um dado sinal, congelam, permanecendo porém prontos 


\section{Urdimento}

${ }^{3}$ Sobre o conceito da 'deriva dos exercícios' ver: Eugenio Barba, A Canoa de Papel-Tratado de Antropologia Teatral (São Paulo: Editora Hucitec, 1994). para recomeçar a correr ao som de um outro sinal, mudando a direção). Comumente, são exercícios agradáveis de se executar. Somos tentados a permanecer por um longo período na sua companhia, como se já fossem, por si, ações teatrais.

No entanto há outros exercícios, de difícil aprendizado e que podem machucar, como, por exemplo, os acrobáticos. Estes parecem ensinar ao ator as fantásticas habilidades do corpo jovem, e, por esta razão, são sempre sedutores. Eles aguçam o reflexo condicionado de precisão e decisão, cruzando os limites do que acreditamos natural. Uma vez dominados e praticados por um longo período, podem ser abandonados. Precisão e decisão devem caracterizar cada simples ação do ator. Como dar um passo, como levantar a mão, como sentar-se ou erguer-se.

Há exercícios calcados em doutrinas do corpo, de respiração e movimento, gratificantes quando parecem chegar às fronteiras do meditativo e espiritual. Outros satisfazem a inventividade e espontaneidade através das milhares de variações da improvisação e seu paradoxo fundamental: o controle das regras da improvisação.

A enumeração de diferentes tipos de exercícios é infinita.

Podemos passar a vida praticando exercícios e improvisações, experimentando um "método" após o outro, explorando os meios como se fossem um fim, continuamente protelando o momento do espetáculo e do encontro com os espectadores. Através destas práticas, nasce uma nova dimensão do amadorismo no teatro (com a superficialidade e dedicação que o distinguem), que suplanta o espetáculo com seminários e cursos. Estes cursos e seminários inserem à vida cotidiana um tempo e um espaço virtuais, e permitem aos participantes viver uns poucos dias no universo teatral, sem a vontade ou a possibilidade real de posteriormente vir a fazer teatro. Tratase de um fenômeno que se disseminou a partir dos primeiros anos do século XX, seguindo a reverberação da pesquisa encabeçada pelos protagonistas da Grande Reforma Teatral. Para alguns deles, o treinamento assumiu tamanho valor, que acabou por transformar-se, de processo, em finalidade absoluta. Esta condição, a deriva dos exercícios ${ }^{3}$, criou situações de atividade que são ilhotas autônomas: nem teatro profissional, nem amador, nem ensaio, nem espetáculo. Temos aqui um dos muitos quartos fantasma do teatro.

Os riscos não são menores quando o treinamento não nos deixa esquecer a necessidade de criar um espetáculo e confrontar-se com os espectadores. Inconscientemente, uma espécie de pequeno dogma pode criarse: o de que o treinamento leva o ator a um renascimento artístico e ético, e, a partir deste, um outro dogma, ainda mais pernicioso, de que o treinamento pode garantir este renascer.

0 Quarto Fantasma. Eugênio Barba. 
Muitos atores, quando questionados sobre o que pensam a respeito do treinamento, exclamam: "Qual o objetivo disto? Eu nem mesmo sei o que é!". É tão fácil ridicularizar os "teatros do treinamento" que, por outro lado, um enfático desejo de defendê-los pode vir à tona com a mesma facilidade.

O treinamento torna-se uma bandeira e um fetiche que acompanha os primeiros anos de experiência teatral fora das escolas e dos teatros "legítimos". Se, então, continuamos, o treinamento evapora da rotina profissional. Ele cria desencantos tão fortes quanto as ilusões que o alimentaram.

Não há nada errado em cultivar ilusões. Ilusões são vitais quando nascem e, ao crescer, transformam-se numa outra coisa. Elas são o único alimento espiritual que nos é dado, os sonhos dos quais somos feitos. Ilusões tornam-se destrutivas quando as deixamos cristalizar e transformar-se em ídolos e dogmas.

\section{Viagens num quarto}

Freqüentemente ouço: "o treinamento é uma parte do trabalho do ator, assim como o é para o músico, o alpinista, o soldado ou o atleta”. A realidade é substancialmente diferente. Em teatro, o termo "treinamento" é usado metaforicamente, e coincide apenas parcialmente com o período de aprendizado ou os exercícios com que se visa manter a forma. Ele não prepara para o espetáculo, tampouco ensina algo. Antes, nos apronta para nos alienarmos do nosso comportamento usual, da chamada espontaneidade, ou da teatralidade convencional.

Quando os mestres da Grande Reforma do século passado, de Stanislavsky a Copeau, de Meyerhold a Dullin ou Decroux, deram tal ênfase aos exercícios, não era a sua intenção apossar-se de uma tradição, mas, ao contrário, refutá-la. Tratava-se de um aprendizado paradoxal, não para uma arte já conhecida, mas uma arte ainda por vir. A partir deste ponto de vista, o treinamento se parece àquilo que, na ciência, distingue a pesquisa pura da pesquisa aplicada.

Motivações similares também estavam na base do treinamento de Grotowski e do Living Theatre. No caso deles, o treinamento específico era uma fuga a um teatro que consideravam como uma prisão, incapaz de dar vida às suas aspirações e vontades.

Totalmente diferentes eram as raízes do treinamento para autodidatas, condição que experimentei pessoalmente com o Odin Teatret. Desde os anos 1970, o treinamento tem sido característica dos jovens que se juntavam em pequenos e independentes grupos underground, forçados ao 
autodidatismo. Éramos os filhos ilegítimos do teatro reconhecido, e não a sua vanguarda. Éramos incapazes de ser incorporados ou de competir com ele. Desde o aprendizado, fomos obrigados a lutar por nossa sobrevivência, fora do reconhecimento das escolas de teatro ou do período de aprendizado em companhias renomadas.

Como órfãos que se identificam com seus avós, louvávamos o etos do ofício e as palavras dos mestres da Grande Reforma, bem como as experiências próximas, como Living Theatre e Grotowski. O Living Theatre e Grotowski podiam parecer marginais ou rejeitados, mas eram aristocratas que haviam rejeitado a legitimidade da cultura teatral da qual se originaram, e na qual haviam cessado de acreditar.

Como autodidatas, nossa recusa era diferente: era uma rejeição devida à nossa inferioridade.

Luto para expor diferenças, mesmo correndo o risco da generalização, para mostrar quão divergentes são os fenômenos, conflitantes as motivações, díspares as rebeliões e esperanças que se fundem no termo "treinamento".

Porém, tanto a recusa dos aristocratas como a dos órfãos têm campos de ação complementares. O primeiro campo de ação possui as vastas dimensões da sociedade, do lugar que o teatro nela ocupa, o espaço do espetáculo, seja ele interno ou externo, fixo ou itinerante, em cidades, com seu público costumeiro, ou em territórios "sem teatro". Nesta geografia, homens e mulheres do teatro testam sua habilidade em criar relações e levar a cabo jornadas reais, quebrando o círculo de suas viagens, da moda ou das marés do mercado.

O outro campo de ação é restrito, e tem o panorama nu de uma jornada ao redor de um quarto aparentemente isolado, onde os atores trabalham consigo mesmos, entre quatro paredes, sem espectadores. É uma situação totalmente diferente do ensaio, em que podemos antever o momento em que os espectadores estarão sentados do outro lado.

Embora pequeno o espaço, a jornada pode ser longa e cheia de lutas. Vista de fora, parece muitas vezes excêntrica e até sem sentido. Vista de dentro, chamada de "exercícios" ou "treinamento", a jornada implica em uma maneira de pensar e uma motivação emocional que se expressam em uma forma de fazer.

\section{Uma identidade profissional diversa}

Eu não estava cego. Estava ciente da existência de atores admiráveis que nunca praticaram forma alguma de treinamento. Por outro lado, alguns atores, que eram excelentes no treinamento, eram desinteressantes no 
espetáculo. Ainda assim, nos meus primeiros anos, estas objeções não me ocorriam, na situação de comprometimento e na descoberta do valor do teatro que o treinamento proporcionava aos meus atores. Eu justificava para mim mesmo - e ainda o creio hoje em dia - a necessidade do treinamento como expressão de uma identidade profissional diversa. Ele era a confirmação diária, humilde e tangível, da decisão de devotar-se ao teatro, através da busca por rigor e autodisciplina. Era a conquista pessoal do ator, do como e do porquê fazer teatro. Forjou as ferramentas de sua independência, crescimento pessoal e capacidade de resistir sob condições adversas. Encorajou cada ator a praticar e defender a dissidência individual e artística.

Um pequeno quarto contém o espaço de uma vasta geografia. É uma solidão sem isolamento, uma solidão acompanhada.

No Odin Teatret, o treinamento persiste ainda hoje, depois de 43 anos. No princípio, ele acontecia em um espaço-tempo zelosamente guardado, sem presenças estranhas. Após mais ou menos 10 anos, tornou-se um quarto mutante. Alguns atores cessaram de entrar nele. Outros perseveraram, transformando este quarto num tapete voador, no seu jardim pessoal, ou numa ilha, onde eram Próspero.

Mesmo quando alguns dos meus atores interromperam o treinamento, mesmo quando eu já não o acompanhava dia após dia, mesmo quando a falta de conexão entre a qualidade do treinamento de um ator e a qualidade do seu resultado no espetáculo tornou-se evidente para todos nós, o treinamento continuou no cerne das minhas reflexões. Uns poucos dos meus atores e eu, cada qual seguindo suas necessidades pessoais, comportavamo-nos como crianças teimosas.

Desta forma, descobrimos que persistir significa mudar a si mesmo. $\mathrm{E}$ as transformações são tão evidentes, que, às vezes, são a negação pura dos pontos de partida.

Um ponto de partida era muito claro no laboratório de Grotowski no início dos anos 1960: não se encena treinamento como espetáculo. Era também peremptório no Odin Teatret: nunca confundir treinamento com ensaio.

Ainda que, exatamente no mesmo período, em 1964, o Living Theatre tenha composto um de seus espetáculos mais radicais - Mysteries and Smaller Pieces - reunindo seus próprios exercícios. Dez anos depois, também o Odin Teatret, no povoado de Carpigiano, sul da Itália, compôs O Livro das Danças, teatralizando o treinamento dos atores. O que aconteceu neste ínterim?

Como Mysteries and Smaller Pieces, O Livro das Danças também se originou de uma série de circunstâncias: tínhamos de nos apresentar aos habitantes do povoado, mas não tínhamos um espetáculo. Construímos uma 
sucessão estruturada de cenas usando exercícios do nosso treinamento, adicionando música, figurinos e uns poucos textos. O resultado permaneceu por vários anos em nosso repertório. Quando paramos de apresentá-lo, ele foi substituído por produções do mesmo tipo. Nesse tempo, o espetáculo do Living Theatre tornara-se um clássico do teatro da segunda metade do século XX. A origem destes dois espetáculos, criados da junção de fragmentos de treinamento, e o fato de haverem sido concebidos quase que por acaso, como produtos extemporâneos, é uma história verdadeira, mas que de qualquer forma não explica as profundas razões do seu nascimento.

Uma mudança acontecera no treinamento, um fato aparentemente desprezível causou uma mutação real: os exercícios estavam fundidos uns aos outros. Desde os nossos primeiros anos no Odin Teatret, percebemos que a força e o efeito do treinamento se multiplicavam, ao invés de executar primeiro um exercício, depois o seguinte, nós os ligávamos uns aos outros, criando um fluir contínuo e duradouro. Desta forma, não era mais o exercício em si que importava, mas o seu final, que se tornava o início do próximo exercício.

Parece um detalhe insignificante, mas as conseqüências práticas explodiram como uma poderosa revolução. Usávamos o termo cadeia para denominar as séries de exercícios contidas num único fluxo. Mas não se tratava realmente de uma cadeia, já que os "pontos de junção" não eram fixos. $\mathrm{O}$ ator começava com uma seqüência pré-estabelecida de mais ou menos dez exercícios já assimilados. O resto era improvisação: a alternância incessante na ordem dos exercícios, acelerando e quebrando seu ritmo, executando-os vigorosa ou suavemente, surpreendendo a si mesmo com mudanças súbitas de direção no espaço. Quanto mais o ator dominasse sua cadeia, melhor ele poderia reagir, criando impulsos simultaneamente. As suas ações eram reações. Possuíam uma textura dinâmica de leveza e vigor semelhante à dança e, se a cadeia fosse acompanhada de música, tinha-se a impressão de um ballet em evolução constante.

A cadeia de exercícios era um repertório de um número limitado de padrões estabelecidos nos mínimos detalhes, que, de toda a forma, podia sempre dar vida a diferentes seqüências, assim como um número limitado de cartas pode dar vida a numerosos e imprevisíveis jogos. Uma vez que o treinamento tomava seu rumo, ele deixava de ser uma prática separada da fase "criativa". Mas a criatividade sempre segue caminhos pessoais. Após alguns anos, não existia mais um "treinamento Odin", e sim diferentes tipos de treinamento, elaborados individualmente pelos atores, com exercícios, justificativas e terminologias que pouco pareciam ter em comum.

No nosso teatro, o tempo do treinamento continua a ser mantido à parte dos ensaios e outros preparativos para um espetáculo. Tornei-me ciente 
de que não mais poderia fazer o papel de um professor que aplica um método comum. Minhas palavras não eram mais capazes de estimular meus atores, e sim minha presença como o outro, a constatar que não sabe mais o propósito do que eles estão fazendo. Eu me questiono quanto ao sentido e à direção dos caminhos solitários, ao longo dos quais o ator se move, a cada manhã, na hora do treinamento.

O termo "treinamento" era cada vez mais inapropriado para o que ocorria na prática. Nós o chamávamos "estanque de peixes". Cada ator trabalhando por si, porém no mesmo espaço. Eles não elaboravam mais as cadeias de exercícios, mas material cênico não-fixado, fragmentos de cenas para futuros espetáculos, grande parte dos quais jamais aconteceria. Uma torrente de imagens, como um magma, preenchia o espaço, cada figura com objetos, tocando instrumentos musicais, usando figurinos incomuns, usando a voz e comportando-se de modo particular. O mesmo ator passava de uma a outra das figuras que havia inventado e desenvolvido.

Num 'estanque de peixes', peixes multicoloridos nadam, alguns efêmeros, outros capazes de crescer e saltar no mar. Cada um deles possui a sua forma embrionária de vida, e nenhum deles é, ainda, dotado de um destino.

A distinção entre treinamento e espetáculo havia claramente desaparecido. Hoje em dia, me é fácil explicar isto em poucas palavras: esta situação se criou porque insistimos neste caminho, sem nos deixar frear pela sensação de que ele não mais tinha utilidade. Mas eu seria insincero se afirmasse que ter prosseguido por este caminho por anos e anos não nos exigiu esforços ou não foi problemático.

Ao mesmo tempo, um processo paralelo e complementar se formava. Ele nasceu de uma necessidade pedagógica: alguns dos atores do Odin destilaram alguns princípios básicos para o treinamento. Estes princípios foram inseridos em exercícios simples, fáceis de aprender, não fixados em formas elaboradas. Funcionavam como terra a ser cultivada, na qual cada aluno poderia plantar seu próprio material, trabalhando autonomamente.

Eu também, ao liderar seminários, deixei de ensinar exercícios, procurando procedimentos que me permitissem individualizar e aplicar os princípios e não as formas. Eu ainda usava a palavra "treinamento" para aquele espaço-tempo, no qual eu era livre para seguir traços que se haviam perdido no nada, demorando-me em mal-entendidos e conjecturas, e infantilmente questionando as verdades óbvias da minha prática. 
Princípios recorrentes em formas diferentes: este é o meu campo de pesquisa - teórica e prática, comparativa e pedagógica, que iniciei com a ISTA, a Escola Internacional de Antropologia Teatral. A antropologia teatral é um estudo comparativo, pragmático, do sistema humano em uma situação de representação organizada. E não é acidental que em cada sessão da ISTA, as primeiras horas do dia sejam devotadas aquilo que um observador chamaria treinamento e exercícios.

\section{O quarto de ninguém?}

A impossibilidade de reduzir o treinamento a uma definição única, a sua mutabilidade e natureza contraditória, seus riscos e fascinação, são fatos concretos. Mas, a que realidade do trabalho teatral pertencem estes fatos?

As origens históricas do treinamento, sua riqueza e variedade, a ilusão da sua virtude de renascimento profissional e a contrastante ilusão de se ser capaz de viver sem ele, indicam mudanças de condição. Mas a quais necessidades correspondem estas mudanças? Talvez o treinamento seja um caso particular de um problema geral? Nesse caso, qual?

Depois de quase 50 anos de prática e estudo do treinamento, estas questões foram imperiosamente jogadas sobre mim por ocasião, em 2005, de uma sessão da Universidade do Teatro Eurasiano, uma atividade regular da ISTA. "Texto e cena”: este tema, por tão óbvio, era objeto de investigação.

Eu imaginava que discutiríamos as maneiras de acordo com as quais um texto se torna espetáculo. Mas, já no primeiro dia, um dos estudiosos abriu um outro front. Ele explicou que, além de interpretação, direção, relação com o espectador e o espaço cênico, havia um problema preliminar: a demanda de se criar uma região intermediária entre os espaços do tex to e do espetáculo. Que região seria esta? Não era, certamente, o período de ensaios.

Franco Ruffini, o estudioso que interrompeu nosso programa, citou o exemplo de Stanislavsky, argumentando que os estratagemas usados por este para dar vida ao texto ou personagem a ser encenado, não eram instrumentos interpretativos. Eram uma acumulação de detalhes interpostos, como uma vasta e volumosa "muralha chinesa", ou como uma terra de ninguém entre a leitura do texto e a sua mise-en-scène. Esta seqüência de detalhes parecia massiva e desproporcional, mas resultava apropriada tão logo se pensasse nela como um modo de povoar o espaço intermediário entre um e outro quarto do teatro: o do texto e o do espetáculo. Os detalhes substanciais não serviam para explorar o texto, mas para fugir a ele, cruzando o denso espaço que estava conectado ao texto, sem pertencer a ele. 
Todos concordamos com o exemplo de Stanislavsky. Mas poderia esta mesma situação ser encontrada em outros casos? Começamos a discutir esta região intermediaria e sem nome. Poderia a sua presença ser generalizada? E do que se tratava, concretamente?

O que se passa neste quarto, e que espaço ele ocupa na construção prática/mental que chamamos "teatro"? Não são os ensaios. Tampouco equivale a trabalhar ao redor de uma mesa, quando o texto é analisado de maneira a fornecer uma interpretação adequada, fiel às intenções do autor, ou às idéias - complementares ou divergentes - dos seus intérpretes.

Este quarto tampouco tem a ver com o espaço de treinamento ou exercícios. O último nos parecia óbvio. No entanto, durante a discussão, esta obviedade foi-se tornando mais e mais questionável.

A idéia de um quarto fantasma ou quarto de ninguém começou a se materializar na nossa discussão. Tentamos defini-lo. Não sabíamos o que ele era, mas o havíamos reconhecido. Ou, antes, ele estava lá, esperando ser reconhecido.

A forma de denominá-lo e a idéia que dele poderíamos ter, nos pareceu ter pouco a ver com teatro. Sua origem estava nas regiões de um certo tipo de literatura na qual sua presença era recorrente. O pesadelo de um "quarto fantasma" ou de um "quarto de ninguém" oferece o roteiro de muitas estórias fantásticas ou de horror. Escritores como Howard Phillips Lovecraft e John Dickson Carr o evocaram, e vem deste último o título "O Quarto de Ninguém”. Pode parecer estranho pensar em estórias deste tipo ao abordar o treinamento, também pelo fato de o 'quarto de ninguém' estar comumente relacionado a um crime. E treinamento não tem nada em comum com crime.

O "quarto fantasma" das estórias e romances é assim chamado porque algumas vezes ele está lá, outras vezes não. Ele se move. O protagonista o viu, por exemplo, na casa de um amigo ou em um castelo, mas ao retornar, não mais o encontra. Ele se pergunta se esteve sonhando, ou, ao contrário, os outros estão mentindo, escondendo um mistério, um tesouro ou delito. A pessoa que vive no lugar, afirma que o quarto que o protagonista viu nunca existiu. Pensam que ele é um louco, ou que está tendo visões.

Em teatro, somos ensinados: há textos para interpretar, há ensaios e espetáculos. Não existe espaço para outras coisas.

Sempre existiram outras coisas. A continuidade do ofício e a troca, por exemplo. Tratando-se de um comércio real, os atores, para sobreviver, deviam possuir diversos artigos "à venda”. Os espetáculos eram mudados quase todos os dias, mantendo vivo um amplo repertório, desperdiçando o mínimo possível 
e criando às pressas. Além dos espetáculos, eles tinham um depósito, onde acumulavam materiais não utilizados, prontos para ser explorados e reciclados: fragmentos, e mesmo cenas inteiras, prontas para ser reaproveitadas. Sempre efetivos, ainda que velhos, esquecidos ou fora de moda, estes materiais estavam sempre aptos a sair do esquecimento, e, através de uma remodelagem, ressurgir como algo novo.

Era o depósito dos clichês, o armário das mais obsoletas convenções. Era a fonte da depressão estética da profissão, de acordo com o julgamento dos reformadores teatrais, que ansiavam por renovação.

O depósito dos clichês sempre esteve escondido na longa história do teatro europeu. Os atores não falavam sobre ele, nem o mostravam, negando, mesmo, a sua existência. Os estetas e reformadores, intuindo a sua presença, sugeriram que se descartasse tudo, deixando entrar o ar novo e fresco do século XX.

O depósito dos clichês tinha serventia cada vez menor em um teatro que deixara de ser um ofício onde os atores preparavam inúmeros espetáculos à sua maneira. O teatro se tornara a atividade dos novos artistas da direção, que cuidavam de cada encenação como uma obra de arte autônoma. O depósito dos clichês tornou-se inútil e daninho, quando o teatro passou a ser considerado uma forma de arte a ser protegida, e não mais um comércio mais ou menos digno.

O depósito dos clichês ficou vazio, e então desapareceu: um quarto fantasma. Então, alguém começou a sentir a sua perda. Nada faltava, já que tudo o que fora perdido, era o que se queria perder. Mas o equilíbrio fora alterado. $\mathrm{O}$ depósito dos clichês desempenhava um papel implícito, não programado, porém essencial: ele criava a consciência do teatro como um país ao qual se pertencia. - o etos profissional. Embora amontoado com restos que se considerava sem valor, era um espaço imaterial, porém concreto. Era a terra de ninguém, interposta entre a vida cotidiana e o espaço dos ensaios e espetáculos. Como o jardim ou o porão, que fica entre a rua e a casa. Os atores podiam andar nele, abrir os armários, onde pedaços de experiências passadas estavam guardados. Para os mais ricos em experiência e talento, era como o quarto da infância, que pais abastados preservaram intacto. Para os mais pobres, era o armário dos seus recursos, de onde podiam tirar o seu magro sustento. Para todos eles, era a sua casa-teatro, seu país-teatro. As viagens incessantes fizeram a sua vida nômade, entretanto, eles carregavam consigo aquele quarto fantasma com o seu próprio teatro, similar ao casco das tartarugas ou à concha dos moluscos. Era um peso que, no entanto, permitia que eles se movessem. 
Todo o trabalho anormal e "desperdiçado" inventado pelos reformadores do século $X X$, quando imaginaram um tempo-espaço para os exercícios, paralelo aos ensaios e espetáculos, visava à reconstrução daquele quarto separado. Eles o esvaziaram de clichês, e encheram-no com novidades.

Diferente do antigo depósito, este novo era apresentável. Tinha a autoridade da boa cultura e era adornado com os valores da ética e da pesquisa. Enquanto que anteriormente ele possa ter parecido inculto e vulgar, ele agora corre o risco de ser sofisticado em demasia. No passado, o depósito dos clichês era o quarto da vergonha e da pilhéria. Hoje em dia, ele está sempre no limiar de tornar-se o santuário do renascimento teatral.

Os riscos e o conteúdo mudam, mas o quarto fantasma continua a existir. É o quarto de ninguém, mesmo sendo o mais pessoal e íntimo. No nosso ofício, o treinamento reside ali, com suas formas fixas, suas motivações individuais e seu valor emocional.

Eu me pergunto: pode o treinamento ser um caso particular de uma demanda geral por um quarto fantasma? Por um espaço onde a necessidade de teatro resida, antes de tornar-se um produto manufaturado?

Quero eu dizer, com isto, que o que chamamos de "treinamento" é apenas uma ilusão e uma fonte de ilusões? Creio que seja exatamente o contrário.

Pretendo sustentar, então, que o treinamento esconde um tesouro objetivo, de superação de obstáculos técnicos e artísticos? Uma vez mais, penso tratar-se do contrário.

Tantas questões permanecem em suspenso, sobre o treinamento, sobre sua oportunidade e qualidade, sobre o que é essencial e o que é mutável, sobre a sua utilidade e seus exageros. Mas uma questão em particular se destaca, parecendo observar tudo isto do lado de fora, como que examinando tudo das nuvens, sem preocupação alguma em aprender ou ambição de reconhecimento artístico. Uma daquelas questões infantis.

Esta criança olha a si mesma e a outras pessoas de teatro. Ela observa o peso que os mantém andando. Aprecia os seus espetáculos. Algumas vezes, balança a cabeça, em negação, outras vezes se comove, abrindo seus olhos para o ar tremulante através do qual o invisível parece espiar por um instante. Ela contempla o grupo, esta companhia difícil e fraterna. 


\section{Urdimento}

E se pergunta: qual o teatro que cada um deles levará consigo, quando eles não mais carregarem o peso do teatro onde cresceram e se formaram?

O teatro do nosso tempo não se parece mais com o dos profissionais do passado. Também não somos mais iniciantes deserdados que precisam inventar seu ofício. Mas ainda temos a necessidade de um teatro portátil, cujas formas e sentido secreto pertençam apenas ao individuo que o faz. "Treinamento" e "quarto fantasma" são apenas palavras, que assumem uma o valor da outra, de acordo com a situação e a época. Nós podemos preencher o teatro que carregamos conosco - seu peso - com materiais que variam de ocasião para ocasião. É a existência deste espaço, deste quarto que pertence somente a nós, que é essencial. Não o que o preenche. 